\title{
Hemoptisis masiva secundaria a un aneurisma de Rasmussen
}

\author{
Massive hemoptysis secondary to a Rasmussen aneurysm
}

Marcelo Parra N. ${ }^{1,2}$, Sofía Delucchi S. ${ }^{1,2}$, Óscar Orellana E. ${ }^{1,2}$ y María Eugenia Casanova K. ${ }^{1,2}$

Paciente masculino de 52 años, Diabetes Mellitus tipo 2 e insuficiencia renal crónica en hemodiálisis, presentó un episodio de hemoptisis masiva. Se realizó un angio-TC de tórax que evidenció un aneurisma de Rasmussen (AR) (Figura 1). Debido al estado general y comorbilidades del paciente se solicitó traslado para manejo mediante radiología intervencional. Sin embargo, esperando el traslado, presenta un $2^{\text {do }}$ episodio de hemoptisis masiva, esta vez asociado a falla ventilatoria requiriendo una lobectomía inferior de emergencia (Figuras 2a, b y c). El abordaje fue por una toracotomía posterolateral, seguido de una laboriosa liberación de adherencias $\mathrm{y}$, finalmente, el control de los elementos vasculares y bronquio del LII. El paciente presentó una evolu- ción satisfactoria, sin compromiso ventilatorio ni mortalidad a 90 días.

El AR es una patología poco frecuente y con altas tasas de mortalidad. Inicialmente descrito en 1868 por Fritz Valdemar Rasmussen en pacientes con cavernas tuberculosas y hemoptisis. Sin embargo, en la actualidad, el término de AR posee un significado más amplio, incluyendo cualquier aneurisma o pseudoaneurisma de las arterias pulmonares en el contexto de enfermedades destructivas del parénquima. Estas producen un debilitamiento progresivo de la pared arterial y la sustitución de las capas adventicia y media por tejido de granulación y fibrina, con el consiguiente adelgazamiento de la pared y riesgo de formación de un pseudoaneurisma ${ }^{1-4}$.
Hospital de Urgencia Asistencia Pública. Santiago, Chile.

${ }^{2}$ Facultad de Medicina de la Universidad Finis Terrae. Santiago, Chile.

Recibido el 20 de marzo de 2018 y aceptado para publicación el 15 de mayo de 2018.

Correspondencia a: Dr. Marcelo Parra N. mfparra@gmail.com

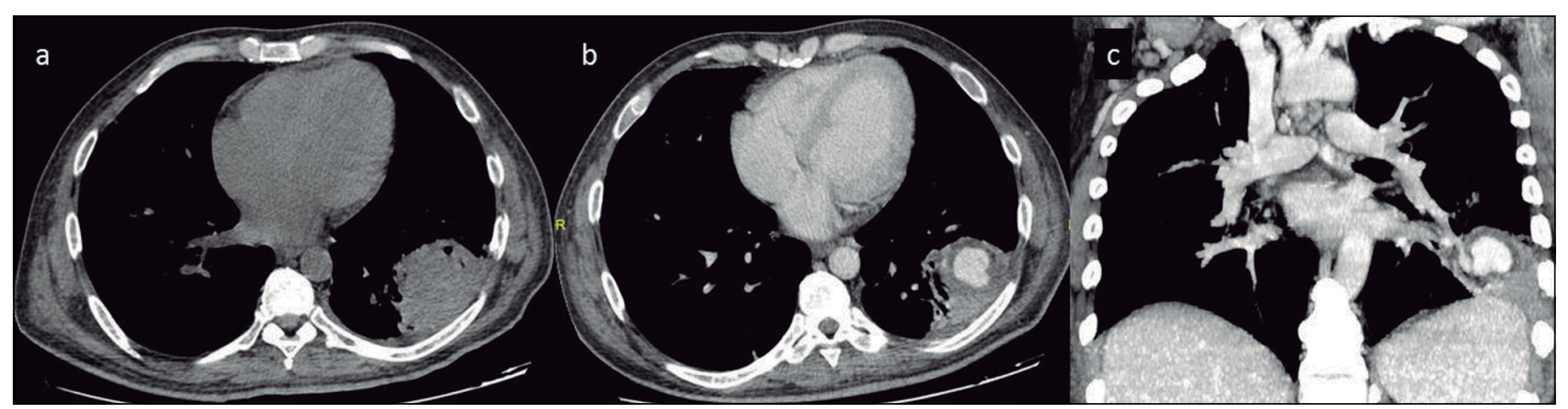

Figura 1. TC tórax. (a) En el segmento basal lateral del LII, se observa una masa pulmonar periférica isodensa, de morfología redondeada y base pleural. (b) Tras la inyección del medio de contraste i.v. se observa realce del área central, con densidad similar al tronco de la arteria pulmonar. (c) Reconstrucción coronal: se observa que esta lesión recibe irrigación de la arteria pulmonar a través de una rama del tronco arterial inferior izquierdo. 
Figura 2. (a) Lóbulo pulmonar inferior izquierdo. Flecha identifica la caverna pulmonar. (b) Lóbulo pulmonar inferior izquierdo. Flecha muestra interior de la caverna llena de coágulos por pseudoaneurisma. (c) Tejido necrótico entremezclado con numerosas hifas anchas, no septadas, de disposición desordenada, sugerente de zigomicosis (HE 100x). (d) Tejido necrótico en el que se destaca, a la izquierda, hifas septadas, ramas dicotómicas, orientadas en la misma dirección, sugerentes de corresponder a Aspergillus, y a la derecha, un grupo de hifas anchas, no septadas, dispuestas desordenadamente, sugerentes de corresponder a una zigomicosis (Grocott 100x).

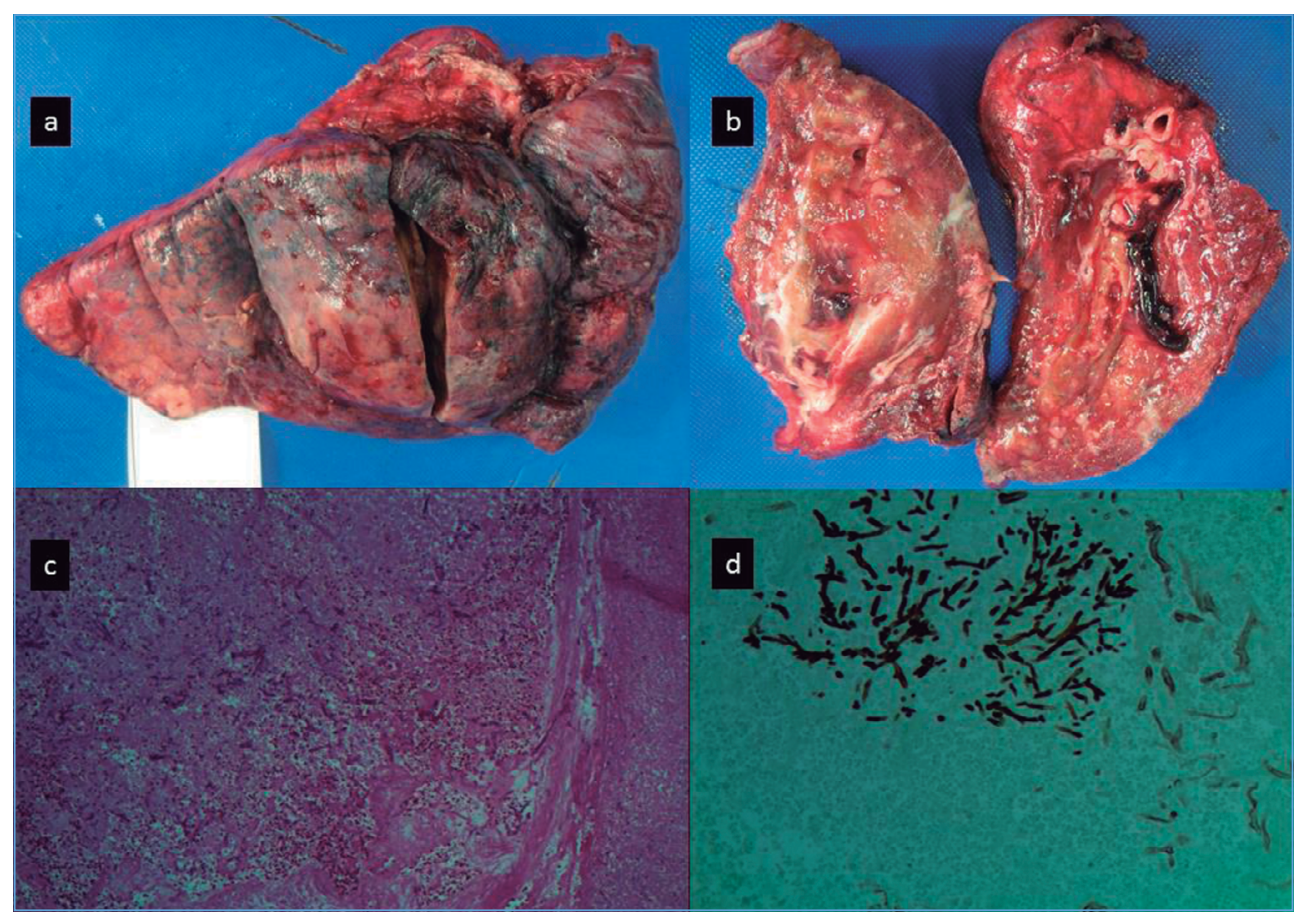

\section{$\underline{\text { Responsabilidades éticas }}$}

Protección de personas y animales. Los autores declaran que para esta investigación no se han realizado experimentos en seres humanos ni en animales.

Confidencialidad de los datos. Los autores declaran que en este artículo no aparecen datos de pacientes.

Derecho a la privacidad y consentimiento informado. Los autores declaran que en este artículo no aparecen datos de pacientes.

\section{Conflicto de intereses}

Los autores no refieren conflictos de interés.

\section{Referencias}

1. Sapra R, Sharma G, Minz A. Rasmussen's aneurysm: A rare and forgotten cause of hemoptysis. Indian Heart J. 2015;67 Suppl 3:S53-6.

2. Van den Heuvel M, J van Rensburg J. Rasmussen's Aneurysm. N Engl J Med. 2006;355:e17.

3. Syed M, Irby J. Airway management of ruptured pulmonary artery Rasmussen aneurysm and massive hemoptysis. BMC Res Notes 2015;12;8:346.

4. Tanahashi Y, Kondo H, Osawa M, Yamamoto T, Yamaguchi M, Furui S. Transcatheter embolization of a Rasmussen aneurysm via pulmonary artery with n-butyl cyanoacrylate and iodized oil mixture injection with balloon occlusion. J Vasc Surg Cases Innov Tech. 2016;2:161-4. 